\title{
PREVALENCE AND ASSOCIATED RISK FACTORS OF SUBSTANCE ABUSE AMONG ADOLESCENTS IN RURAL COMMUNITIES, CENTRAL THAILAND: A CROSS-SECTIONAL STUDY
}

\author{
Wassamon Yaimai*, Kanokwan Oopakarn*, Chatsiri Phumvichitr*, Charita Anukulkijkul*, Napat Phonnopparat*, \\ Natnicha Yindeepolcharoen*, Tanunchol Uthong*, Napak Charoenjai*, Narisara Rachapongthai*, Ratthanan Theeraphanvikul*, \\ Sarun Ruanma*, Supakorn Soontrapornchai*, Sutinee Srimahachota*, Wanida Rattanasumawong**, Ram Rangsin***, \\ Boonsub Sakboonyarat*** \\ $* 4^{\text {th }}$ Year Medical Cadets, Phramongkutklao College of Medicine, Bangkok, Thailand \\ ** Department of Psychiatry and Neurology, Phramongkutklao College of Medicine, Bangkok, Thailand \\ *** Department of Military and Community Medicine, Phramongkutklao College of Medicine, Bangkok, Thailand
}

\begin{abstract}
Background: Substance abuse is one serious social challenge that has continued to increase over a long time. This major problem currently affects society, the economy and national development. One related study conducted in southern Thailand found that the prevalence of substance abuse in youth groups was $7 \%$ in 2002 increasing to $9 \%$ and $13 \%$ in 2003 and 2004, respectively. Nevertheless, information regarding substance abuse among adolescents in Thailand remains limited especially in remote rural communities. The study aimed to determine the prevalence and associated factors concerning substance abuse.

Methods: The present study was conducted in 2 high schools in rural communities, Chachoengsao and Sa Kaeo Provinces, central Thailand. A cross-sectional quantitative study identified the prevalence and associated factors of substance abuse among adolescents. A standardized self-reported questionnaire was used to collect data including demographic characteristics, history of substance abuse and associated factors. Multivariate analysis was performed to adjust confounders using logistic regression analysis.

Results: The sample size of the study totaled 652 adolescents. The lifetime prevalence of substance abuse was $24.4 \%$, while the one-year prevalence of substance abuse was $16.7 \%$. After adjusting for potential confounders, the risk factors associated with one year substance abuse among adolescents were being male (AORs; $2.19,95 \% \mathrm{CI} ; 1.16-4.16$ ), friend inducement (AORs; 3.28, 95\% CI; 1.64-6.55), smoking (AORs; 3.22, 95\%CI; 1.50-6.90) and alcohol consumption (AORs; 4.46, 95\%CI; 2.43-8.16).

Conclusion: Our data emphasized that substance abuse was a problem in these rural communities. Public health interventions aimed to prevent substance abuse among adolescents should be designed and provided for these rural communities. Further, schools should provide lessons how to negotiate and avoid coercion when being induced to abuse substances or other unhealthy and dangerous behaviors.
\end{abstract}

Keywords : Substance abuse, adolescents, rural community, Thailand

J Southeast Asian Med Res 2019; 3(2): 73-81.

http://www.jseamed.org

Correspondence to:

Sakboonyarat B, Department of Military and Community Medicine, Phramongkutklao College of Medicine, Bangkok, Thailand

Email: boonsub1991@pcm.ac.th 


\section{Introduction}

Substance abuse represents one serious social challenge that has continued to increase over a long time. It constitutes one of the major problems currently affecting society, the economy and national development. ${ }^{(1,2)}$ Moreover, illicit drugs affect several aspects among users including emotional, social, physical and mental health. ${ }^{(3,4)}$ Because all drugs directly affect the brain, using highly addictive drugs many consecutive times will eventually lead to addiction. Importantly, drug addiction leads to many complications including psychosis, depression and aggressive behaviors. ${ }^{(5,6)}$ At present, the Thai government provides a great deal of funding and other resources to manage drug problems. The government has used both internal and collaborative efforts with the awareness that narcotics may contribute to social problems such as crime, prostitution and gambling. These problems threaten national security, public order, moral practices and the economy. However, substance abuse is still escalating among adolescents. One related study in southern Thailand found that the prevalence of substance abuse in youth groups was $7 \%$ in 2002 increasing to $9 \%$ and $13 \%$ in 2003 and 2004, respectively. ${ }^{(7)}$

One half of areas in Thailand are still rural (47\%) where healthcare provider characteristics and health literacy differ from those of urban communities especially in remote rural areas. ${ }^{(8)}$ Nevertheless, information regarding substance abuse among adolescents in Thailand remains limited especially in remote rural communities. Additionally, adolescents constitute a teenage population who will grow up to become adults soon. However, these young people are more likely to become addicted to illegal substances due to developmental changes in the neural circuitry involved in reward processing. ${ }^{(9)}$ This study aimed to determine the prevalence and associated risk factors of substance abuse among adolescents in remote rural communities in central Thailand. When substance issues of adolescents are detected and solved early on, the complications of addiction may be attenuated.

\section{Methods}

The present study was conducted in two high schools in rural communities, Chachoengsao and Sa Kaeo Provinces, central Thailand, $160 \mathrm{~km}$ east of Bangkok. This remote, isolated community totaled 15,000 villagers, mostly farmers. Schools no. 1 and no.2 are government high schools providing education in grades 7 to 12 for adolescents residing in peripheral areas of schools. Both schools were chosen to represent schools in remote rural communities in central Thailand. A cross-sectional quantitative study identified the prevalence and associated factors of substance abuse among adolescents. The survey was conducted among 451 students in school no. 1 and 201 students in school no. 2. A standardized self-reported questionnaire was used to collect data including demographic characteristics, history of substance abuse and associated factors. The questionnaires were self-administered and delivered in an envelope. However, names and identities of the volunteers in the study were kept confidential. We checked the collected data using double-data entry for accuracy and completeness and then coded, entered and analyzed the data using IBM SPSS Statistics for Windows, Version 23.0. Frequency distribution of demographic characteristics and behavioral data were calculated to determine descriptive statistics of the sample. Chi-square test was used to compare frequency distribution of categorical variables by strata, while binary logistic regression analysis was used to determine the risk factors associated with substance abuse. The magnitude of association was presented as crude odds ratios (ORs) with $95 \%$ confidence interval (CI). A $p$-value less than 0.05 was considered statistically significant. Multivariate analysis was performed to adjust confounders using logistic regression analysis using the backward elimination method (Wald).

This study was reviewed and approved by the Institutional Review Board, Royal Thai Army Medical Department. Consent forms were completed by the main guardian of each adolescent and adolescents before they participated in the study.

\section{Results}

The sample size of the study totaled 652 adolescents. The response rate of schools no.1 and no.2 accounted for $75.2 \%$ and $71.0 \%$, respectively. Descriptive characteristics of the study sample are presented in Table 1. In all, 451 $(69.2 \%)$ students were from school no.1 in Chacheongsao 
Table1. Demographic characteristics of the enrolled school children

\begin{tabular}{|c|c|c|}
\hline Characteristics & $\mathbf{n}$ & (\%) \\
\hline \multicolumn{3}{|l|}{ Age (years) } \\
\hline mean \pm S.D. & & $14.87 \pm 1.70$ \\
\hline $\min -\max$ & & $12-19$ \\
\hline \multicolumn{3}{|l|}{ School } \\
\hline No. 1 & 451 & $(69.2)$ \\
\hline No. 2 & 201 & $(30.8)$ \\
\hline \multicolumn{3}{|l|}{ Sex } \\
\hline Male & 270 & $(41.7)$ \\
\hline Female & 378 & $(58.3)$ \\
\hline \multicolumn{3}{|l|}{ Grade } \\
\hline $7^{\text {th }}$ & 125 & $(19.2)$ \\
\hline $8^{\text {th }}$ & 142 & $(21.8)$ \\
\hline $9^{\text {th }}$ & 122 & (18.7) \\
\hline $10^{\text {th }}$ & 89 & (13.7) \\
\hline $11^{\text {th }}$ & 106 & (16.3) \\
\hline $12^{\text {th }}$ & 68 & $(10.4)$ \\
\hline \multicolumn{3}{|l|}{ Religion } \\
\hline Buddhism & 641 & $(98.3)$ \\
\hline Christian & 9 & (1.4) \\
\hline Others & 2 & $(0.3)$ \\
\hline \multicolumn{3}{|c|}{ History of school suspension } \\
\hline No & 620 & 96.9 \\
\hline Yes & 20 & 3.1 \\
\hline \multicolumn{3}{|c|}{ History of parents being called by teacher } \\
\hline No & 608 & $(95.3)$ \\
\hline Yes & 30 & $(4.7)$ \\
\hline \multicolumn{3}{|c|}{ Family income per year (baht) } \\
\hline$<50000$ & 80 & $(51)$ \\
\hline$\geq 50000$ & 77 & (49) \\
\hline \multicolumn{3}{|c|}{ GPA $1^{\text {st }}$ semester 2017} \\
\hline mean \pm S.D. & & $2.82 \pm 0.62$ \\
\hline \multicolumn{3}{|l|}{ GPA 2016} \\
\hline mean \pm S.D. & & $2.84 \pm 0.67$ \\
\hline
\end{tabular}


and $201(30.8 \%)$ students were from school no. 2 in Sa Kaeo. In all, male participants accounted for $41.7 \%$. The average age of participants was $14.8 \pm 1.7$ years.

The lifetime prevalence of substance abuse was $24.4 \%$. The one-year prevalence of substance abuse was $16.7 \%$ with a higher prevalence noted among males (24.1\%) than females (11.6\%). Figure 1 shows the prevalence of substances abuse among adolescents in rural communities stratified by type of substance. Cannabis was the most commonly abused substance on a lifetime basis accounting for $4.4 \%$. Univariate and multivariate logistic regression analyses were performed to determine the factors associated with one year substance abuse as shown in Tables $\mathbf{2}$ and 3. After adjusting for potential confounders, the risk factors associated with one year substance abuse among adolescents included being male (adjusted odds ratio (AORs); 2.19, 95\%CI; 1.16-4.16), friend inducement (AORs; 3.28, 95\%CI; 1.64-6.55), smoking (AORs; 3.22, $95 \% \mathrm{CI} ; 1.50-6.90)$ and alcohol consumption (AORs; $4.46,95 \% \mathrm{CI} ; 2.43-8.16$ ).

\section{Discussion}

The lifetime prevalence of substance abuse among adolescents in the present study was $24.4 \%$, which was relatively high compared with one related study in southern Thailand. ${ }^{(7)}$ A recent study conducted among high school years 7,9 and 11 and vocational students to determine the situation of substance abuse among adolescents in both urban and rural areas in southern Thailand showed an overall lifetime prevalence of illicit drug use accounting for 5 to $7 \%$. ${ }^{(7)}$ Another study in four regions of Thailand conducted between 2001 and 2011 reported the lifetime prevalence of illicit drug use accounted for 5.4 to $7.3 \% .^{(10)}$ Additionally, one recent report in 2015 illustrated that the lifetime prevalence of substance use among adolescent students was $12.7 \%$. $^{(11)}$

Obviously, the trend in the lifetime prevalence of substance use continuously rose overtime. The study found that the one year prevalence of substance abuse among adolescents in rural Thailand was $16.7 \%$. Compared with one year prevalence of substance abuse among adolescents in our study, the one year prevalence of those in one related study in 2004 was relatively low. ${ }^{(7)}$

Fig 1. Prevalence of substance use among adolescents in the rural communities stratified by type of substance

\section{Prevalence of substance use among adolescents in the rural}

$$
\text { communities } \square \text { Past } 12 \text { months } \square \text { Life-time }
$$

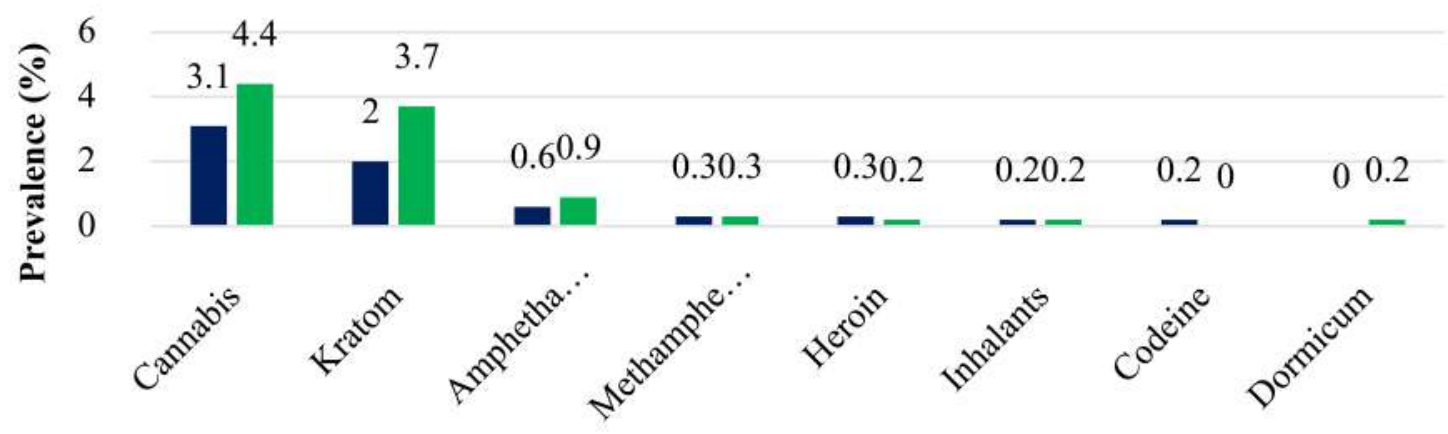

Substances 
Table 2. Univariate analysis for factors associated with one year substance used

\begin{tabular}{|c|c|c|c|c|c|}
\hline \multirow{3}{*}{ Factors } & \multicolumn{2}{|c|}{ Substance used } & \multirow{3}{*}{ Crude ORs } & \multirow{3}{*}{$95 \%$ CI } & \multirow{3}{*}{$p$-value } \\
\hline & No & Yes & & & \\
\hline & n (\%) & n (\%) & & & \\
\hline \multicolumn{6}{|l|}{ Sex } \\
\hline Female & $334(88.4)$ & $44(11.6)$ & 1 & & \\
\hline Male & $205(75.9)$ & $65(24.1)$ & 2.41 & $(1.58-3.66)$ & $<0.001$ \\
\hline \multicolumn{6}{|l|}{ Age (year) } \\
\hline mean \pm S.D. & $14.8 \pm 1.7$ & $15.1 \pm 1.6$ & 1.11 & $(0.98-1.25)$ & 0.096 \\
\hline \multicolumn{6}{|l|}{ School } \\
\hline School 2 & $175(87.1)$ & $26(12.9)$ & 1 & & \\
\hline School 1 & $368(81.6)$ & $83(18.4)$ & 1.52 & $(0.94-2.44)$ & 0.086 \\
\hline \multicolumn{6}{|l|}{ Grade } \\
\hline $7^{\text {th }}-9^{\text {th }}$ & $326(83.8)$ & $63(16.2)$ & 1 & & \\
\hline $10^{\text {th }}-12^{\text {th }}$ & $217(82.5)$ & $46(17.5)$ & 1.09 & $(0.72-1.67)$ & 0.664 \\
\hline \multicolumn{6}{|l|}{ GPAX } \\
\hline$\geq 3.00$ & $268(85.1)$ & $47(14.9)$ & 1 & & \\
\hline$<3.00$ & $157(83.5)$ & $31(16.5)$ & 1.13 & $(0.69-1.85)$ & 0.638 \\
\hline \multicolumn{6}{|c|}{ History of school suspension } \\
\hline No & $523(84.4)$ & $97(15.6)$ & 1 & & \\
\hline Yes & $13(65.0)$ & $7(35.0)$ & 2.9 & $(1.13-7.46)$ & 0.027 \\
\hline \multicolumn{6}{|c|}{ History of parents being called by teacher } \\
\hline No & $517(85.0)$ & $91(15.0)$ & 1 & & \\
\hline Yes & $17(56.7)$ & $13(43.3)$ & 4.35 & $(2.04-9.25)$ & $<0.001$ \\
\hline \multicolumn{6}{|l|}{ Parents' marital status } \\
\hline Married & $336(83.4)$ & $67(16.6)$ & 1 & & \\
\hline Widow & $16(72.7)$ & $6(27.3)$ & 1.88 & $(0.71-4.98)$ & 0.204 \\
\hline Divorced/Separated & $189(84.0)$ & $36(16.0)$ & 0.96 & $(0.61-1.49)$ & 0.839 \\
\hline \multicolumn{6}{|l|}{ Main guardian } \\
\hline Father/Mother & $367(82.3)$ & $79(17.7)$ & 1 & & \\
\hline Ohers & $176(85.4)$ & $30(14.6)$ & 0.79 & $(0.50-1.25)$ & 0.317 \\
\hline \multicolumn{6}{|l|}{ Siblings } \\
\hline One or more sibling & $409(83.1)$ & $83(16.9)$ & 1 & & \\
\hline No sibling & $134(83.8)$ & $26(16.3)$ & 0.96 & $(0.59-1.55)$ & 0.855 \\
\hline \multicolumn{6}{|l|}{ Residency } \\
\hline Home & $523(83.4)$ & $104(16.6)$ & 1 & & \\
\hline Others & $18(78.3)$ & $5(21.7)$ & 1.39 & $(0.51-3.85)$ & 0.518 \\
\hline \multicolumn{6}{|c|}{ Family income per year (baht) } \\
\hline$<50000$ & $69(86.3)$ & $11(13.8)$ & 1 & & \\
\hline
\end{tabular}


Table 2. Univariate analysis for factors associated with one year substance used

\begin{tabular}{|c|c|c|c|c|c|}
\hline \multirow{3}{*}{ Factors } & \multicolumn{2}{|c|}{ Substance used } & \multirow{3}{*}{ Crude ORs } & \multirow{3}{*}{$95 \%$ CI } & \multirow{3}{*}{$p$-value } \\
\hline & \multirow{2}{*}{$\begin{array}{r}\text { No } \\
\text { n (\%) }\end{array}$} & \multirow{2}{*}{$\begin{array}{r}\text { Yes } \\
\text { n (\%) }\end{array}$} & & & \\
\hline & & & & & \\
\hline$\geq 50000$ & $61(79.2)$ & $16(20.8)$ & 1.65 & $(0.71-3.82)$ & 0.246 \\
\hline \multicolumn{6}{|l|}{ Social media use } \\
\hline No & $285(83.6)$ & $56(16.4)$ & 1 & & \\
\hline Yes & $258(83.0)$ & $53(17.0)$ & 1.05 & $(0.69-1.58)$ & 0.832 \\
\hline \multicolumn{6}{|c|}{ Having boyfriend/girlfriend } \\
\hline No & $401(85.1)$ & $70(14.9)$ & 1 & & \\
\hline Yes & $142(78.5)$ & $39(21.5)$ & 1.57 & $(1.02-2.43)$ & 0.042 \\
\hline \multicolumn{6}{|l|}{ Regular exercise } \\
\hline No & $283(84.5)$ & $52(15.5)$ & 1 & & \\
\hline Yes & $254(82.2)$ & $55(17.8)$ & 1.18 & $(0.78-1.79)$ & 0.438 \\
\hline \multicolumn{6}{|l|}{ Having love problems } \\
\hline No & $350(85.6)$ & $59(14.4)$ & 1 & & \\
\hline Yes & $189(79.1)$ & $50(20.9)$ & 1.569 & $(1.035-2.38)$ & 0.034 \\
\hline \multicolumn{6}{|c|}{ Having academic problems } \\
\hline No & $354(86.8)$ & $54(13.2)$ & 1 & & \\
\hline Yes & $189(77.5)$ & $55(22.5)$ & 1.91 & $(1.26-2.89)$ & 0.002 \\
\hline \multicolumn{6}{|c|}{ Having financial problems } \\
\hline No & $268(85.4)$ & $46(14.6)$ & 1 & & \\
\hline Yes & $275(81.4)$ & $63(18.6)$ & 1.34 & $(0.88-2.02)$ & 0.173 \\
\hline \multicolumn{6}{|c|}{ Having family problems } \\
\hline No & $379(87.1)$ & $56(12.9)$ & 1 & & \\
\hline Yes & $164(75.6)$ & $53(24.4)$ & 2.19 & $(1.44-3.32)$ & $<0.001$ \\
\hline \multicolumn{6}{|c|}{ Friend inducement of substance abuse } \\
\hline No & $467(88.4)$ & $61(11.6)$ & 1 & & \\
\hline Yes & $50(59.5)$ & $34(40.5)$ & 5.21 & $(3.12-8.68)$ & $<0.001$ \\
\hline \multicolumn{6}{|c|}{ Family member involves in addictive substance } \\
\hline No & $450(85.1)$ & $79(14.9)$ & 1 & & \\
\hline Yes & $63(74.1)$ & $22(25.9)$ & 1.99 & $(1.15-3.42)$ & 0.013 \\
\hline \multicolumn{6}{|l|}{ Smoking } \\
\hline No & $499(89.1)$ & $61(10.9)$ & 1 & & \\
\hline Yes & $44(47.8)$ & $48(52.2)$ & 8.92 & $(5.48-14.54)$ & $<0.001$ \\
\hline \multicolumn{6}{|l|}{ Alcohol drinking } \\
\hline No & $375(91.0)$ & $37(9.0)$ & 1 & & \\
\hline Yes & $168(70.0)$ & $72(30.0)$ & 4.34 & $(2.81-6.72)$ & $<0.001$ \\
\hline
\end{tabular}


Table 3. Multivariate analysis for factors associated with one year substance used

\begin{tabular}{|c|c|c|c|c|c|}
\hline \multirow[b]{2}{*}{ Factors } & \multicolumn{2}{|c|}{ Substance used } & \multirow[b]{2}{*}{$\begin{array}{l}\text { Adjusted } \\
\text { ORs }\end{array}$} & \multirow[b]{2}{*}{$95 \%$ CI } & \multirow[b]{2}{*}{$p$-value } \\
\hline & $\begin{array}{c}\text { No } \\
\text { n (\%) }\end{array}$ & $\begin{array}{c}\text { Yes } \\
\text { n (\%) }\end{array}$ & & & \\
\hline \multicolumn{6}{|l|}{ Sex } \\
\hline Female & $334(88.4)$ & $44(11.6)$ & 1 & & \\
\hline Male & $205(75.9)$ & $65(24.1)$ & 2.19 & $1.16-4.16$ & 0.016 \\
\hline \multicolumn{6}{|c|}{ Friend inducement of substance abuse } \\
\hline No & $467(88.4)$ & $61(11.6)$ & 1 & & \\
\hline Yes & $50(59.5)$ & $34(40.5)$ & 3.28 & $1.64-6.55$ & 0.001 \\
\hline \multicolumn{6}{|l|}{ Smoking } \\
\hline No & $499(89.1)$ & $61(10.9)$ & 1 & & \\
\hline Yes & $44(47.8)$ & $48(52.2)$ & 3.22 & $1.50-6.90$ & 0.003 \\
\hline \multicolumn{6}{|c|}{ Alcohol drinking } \\
\hline No & $375(91.0)$ & $37(9.0)$ & 1 & & \\
\hline Yes & $168(70.0)$ & $72(30.0)$ & 4.46 & $2.43-8.16$ & $<0.001$ \\
\hline
\end{tabular}

Multivariate analysis (Backward Wald): adjusted for gender, friend inducement of substance use, smoking and alcohol drinking

The phenomenon may be explained by geographic area. The present study was conducted in remote rural communities where healthcare provider characteristics and health literacy differ from those of urban communities especially in remote rural areas. ${ }^{(8)}$ Local people including adolescents and young adults may lack health literacy regarding the burden of illicit drugs as well as their complications. ${ }^{(12,13)}$

Most studies found that substance abuse was more common among male adolescents. ${ }^{(7,10,14)}$ In the present study, the prevalence of substance use among male adolescents was significantly higher as well. In the study, cannabis was the most commonly used substance with overall rate of one year abuse accounting for $3.1 \%$. A similar result was found in one report from Thailand in 2001. ${ }^{(10)}$ Cannabis is easy to access and cheaper than other illicit substances. Furthermore, cannabis is easy to cultivate in Southeast Asia and carries lower penalties compared with other illicit substances such as amphetamines. Similarly, kratom, Mitragyna speciosa, which has been traditionally used for both their stimulant properties as well as an opium substitute, ${ }^{(15)}$ was the second most commonly used substance among adolescents accounting for $2 \%$. One related study in Thailand illustrated that both cannabis and kratom were the most common one year use substances among adolescents. ${ }^{(7)}$ Adolescents may perceive that they take less risk in trying kratom than other substances; moreover, kratom is an addictive plant commonly found in Thailand and traditionally used by villagers especially in rural areas. Some villagers believed that kratom may enhance work performance by increasing endurance and tolerance and that it can be used to attenuate fatigue and treat some illnesses. $^{(16)}$

Factors related to substance abuse included being male, friends persuaded to try the substance, smoking and alcohol consumption in the past 12 months. Among male adolescents, the prevalence of drug use was 2.19 times greater than that among female adolescents due to the nature of life style among friends and interests that differed from females. ${ }^{(17)}$ Persuasion to use drugs in a group of friends increases the risk of substance abuse up to 3.28 times because Thai teenagers often join together as a group of friends and are at the age of wanting to be accepted by friends. Thus, adolescents are often persuaded in their group of friends to do something, to make themselves accepted by their group members. ${ }^{(18)}$ Alcohol consumption in the past 12 months has been found to be related to substance use 4.46 times higher than nonalcohol consumption. Because alcohol is often consumed in a 
group setting it can lead to loss of self-esteem, wherein they tend to be easily persuaded to use illicit drugs. ${ }^{(19)}$ Smoking was found to be another factor related to substance abuse. Nicotine, the main addictive chemical in tobacco smoke, can induce dopamine release in the brain in a reward circuit creating a desire for other substances. Additionally, related studies have reported that adolescent nicotine exposure influences long term biochemical and functional changes in the brain that encourages subsequent drug use. ${ }^{(20,21)}$

The limitations of this study were that only students from two schools were included in this study so it could not represent the whole population in rural communities. The study employed a cross-sectional design, making it difficult to establish a cause-and-effect relationship between associated factors and substance abuse.

In conclusion, the study showed a high prevalence of substance use among adolescents and associated factors included being male, friend inducement, smoking and alcohol consumption. The adolescents were in the age group that receives various social influences. Therefore, we should focus on this problem. Public health interventions aimed to prevent and reduce substance abuse should be designed so that these adolescents can grow into quality adults in the future.

\section{Acknowledgements}

The authors express their grateful thanks to all participants of the survey and to the staff of both secondary schools in Chacheongsao and Sa Kaeo Provinces. The authors wish to thank the entire staff members of the Department of Military and Community Medicine and Department of Psychiatry and Neurology, Phramongkutklao College of Medicine, for their support in completing this study.

\section{References}

1. Patrick ME, Wightman P, Schoeni RF, Schulenberg JE. Socioeconomic status and substance use among young adults: a comparison across constructs and drugs. J Stud Alcohol Drugs 2012; 73: 772-82.

2. Daley DC. Family and social aspects of substance use disorders and treatment. J Food Drug Anal 2013; 21: S73-S6

3. Pengpid S, Peltzer K. Prevalence and psychosocial correlates of illicit drug use among school-going. adolescents in Thailand. J Soc Sci 2013; 34: 269-75. Lander L, Howsare J, Byrne M. The impact of substance use disorders on families and children: from

4. theory to practice. Soc Work Public Health 2013; 28: 194-205.

DiMiceli LE, Sherman SG, Aramrattana A, Sirirojn B, Celentano DD. Methamphetamine use is associated

5. with high levels of depressive symptoms in adolescents and young adults in Rural Chiang Mai Province, Thailand. BMC Public Health. 2016; 16: 168.

Substance Abuse and Mental Health Services Administration (SAMHSA). Substance abuse treatment for

6. persons with co-occurring disorders. SAMHSA/CSAT Treatment improvement protocols. Rockville, MD: Center for Substance Abuse Treatment; 2005.

Assanangkornchai S, Pattanasattayawong U, Samangsri N, Mukthong A. Substance use among high-school stu-

7. dents in Southern Thailand: trends over 3 years (2002-2004). Drug Alcohol Depend 2007; 86: 167-74. The World urbanization prospects, the 2011 revision. the UN Population Division, Department of Economic and

8. Social Affairs (DESA), United Nations Secretariat. 2014. Hammond CJ, Mayes LC, Potenza MN. Neurobiology of adolescent substance use and addictive behaviors:

9. treatment implications. Adolesc Med State Art Rev 2014; 25: 15-32.

Angkurawaranon C, Jiraporncharoen W, Likhitsathian S, Thaikla K, Kanato M, Perngparn U, et al. Trends in 10. the use of illicit substances in Thailand: Results from national household surveys. Drug Alcohol Rev 2018; 37: 658-63.

11. Chomsri P, Aramrattana A, Siviroj P, Likhitsathian S. Substance use among students in Thailand. J Ethn Subst Abuse 2018: 1-13.

12. Conger RD.. The special nature of rural America. In Robertson EB, Sloboda Z,. Boyd GM, Beatty L, Kozel NJ. (Eds.), Rural substance abuse: State of knowledge and issues, NIDA research monograph 1997b: 168 pp. 37-52. Rockville, MD: National Institute on Drug 13. Abuse. DeVoe JE, Krois L, Stenger R. Do children in rural areas still have different access to health care? Results from a statewide survey of Oregon's food stamp population. J Rural Health 2009; 25: 1-7. 
14. Pengpid S, Peltzer K. .Prevalence and psychosocial correlates of illicit drug use among school-going adolescents in Thailand. J Soc Sci 2013; 34: 269-75.

15. Adkins JE, Boyer EW, McCurdy CR. Mitragyna speciosa, a psychoactive tree from Southeast Asia with opioid activity. Cur Top Med Chem 2011; 11: 1165-75.

16. Assanangkornchai S, Muekthong A, Sam-Angsri N, Pattanasattayawong U. The use of Mitragynine speciosa ("Krathom"), an addictive plant, in Thailand. Subst Use Misuse 2007; 42: 2145-57.

17. Becker JB, McClellan ML, Reed BG. Sex differences, gender and addiction. Journal Neurosci Res 2017; 95: $136-47$.
18. Laursen B, Hafen CA, Kerr M, Stattin H. Friend influence over adolescent problem behaviors as a function of relative peer acceptance: to be liked is to be emulated. $\mathrm{J}$ Abnorm Psychol 2012; 121: 88.

19. Assanangkornchai S, Mukthong A, Intanont $\mathrm{T}$. Prevalence and patterns of alcohol consumption and health-risk behaviors among high school students in Thailand. Alcohol Clin Exp Res 2009; 33: 2037-46.

20. Weinberger AH, Sofuoglu M. The impact of cigarette smoking on stimulant addiction. Am J Drug Alcohol Abuse 2009; 35: 12-7.

21. Ren M, Lotfipour S. Nicotine Gateway Effects on Adolescent Substance Use. The West J Emerg Med 2019; 20: 696-709. 